\title{
Advances and Prospects in Tissue-Engineered Meniscal Scaffolds for Meniscus Regeneration
}

\author{
Weimin Guo, Shuyun Liu, Yun Zhu, Changlong Yu, Shibi Lu, Mei Yuan, \\ Yue Gao, Jingxiang Huang, Zhiguo Yuan, Jiang Peng, Aiyuan Wang, Yu Wang, \\ Jifeng Chen, Li Zhang, Xiang Sui, Wenjing Xu, and Quanyi Guo
}

Institute of Orthopaedics, Chinese PLA General Hospital, 28 Fuxing Road, Haidian District, Beijing 100853, China

Correspondence should be addressed to Quanyi Guo; doctorguo_301@163.com

Received 23 March 2015; Revised 1 June 2015; Accepted 9 June 2015

Academic Editor: Susan Liao

Copyright (C) 2015 Weimin Guo et al. This is an open access article distributed under the Creative Commons Attribution License, which permits unrestricted use, distribution, and reproduction in any medium, provided the original work is properly cited.

\begin{abstract}
The meniscus plays a crucial role in maintaining knee joint homoeostasis. Meniscal lesions are relatively common in the knee joint and are typically categorized into various types. However, it is difficult for inner avascular meniscal lesions to self-heal. Untreated meniscal lesions lead to meniscal extrusions in the long-term and gradually trigger the development of knee osteoarthritis (OA). The relationship between meniscal lesions and knee OA is complex. Partial meniscectomy, which is the primary method to treat a meniscal injury, only relieves short-term pain; however, it does not prevent the development of knee OA. Similarly, other current therapeutic strategies have intrinsic limitations in clinical practice. Tissue engineering technology will probably address this challenge by reconstructing a meniscus possessing an integrated configuration with competent biomechanical capacity. This review describes normal structure and biomechanical characteristics of the meniscus, discusses the relationship between meniscal lesions and knee OA, and summarizes the classifications and corresponding treatment strategies for meniscal lesions to understand meniscal regeneration from physiological and pathological perspectives. Last, we present current advances in meniscal scaffolds and provide a number of prospects that will potentially benefit the development of meniscal regeneration methods.
\end{abstract}

\section{Introduction}

The meniscus is one of the most commonly damaged areas of the knee joint, which was once considered a "functionless remnant of leg muscle origin" [1]. The mean incidence of meniscal injury in the United States is $66 / 100,000[2,3]$. Completely removing the meniscus was the major treatment for meniscal injuries in 1889, and this treatment prevailed for nearly 80 years [4]. However, a number of follow-up radiographic studies from the late 1960s to the 1980s reported a high frequency of knee osteoarthritis (OA) after total removal of the meniscus [5-7]. Clinical follow-up results also showed knee OA in all patients 14 years after partial meniscectomy $[8,9]$, which is the current primary method to treat meniscal injuries.

Menisci play a crucial role maintaining knee joint function, including transmitting load, absorbing shock, stabilizing the knee joint, and providing nutrition to the joint [10-14].
It is important to ensure that meniscal integrity maintains knee joint homeostasis from a surgical treatment strategy perspective [15-19]. Tissue engineering brings new hope to restore an intact meniscus with competent function. This review summarizes meniscal structure and biomechanical properties, the relationship between meniscal lesions and the development of knee OA, lesion classifications, and therapeutic strategies from physiological and pathological perspectives. We focus on advances in tissue-engineered meniscal scaffolds and provide some regenerative strategies that may potentially benefit the development of meniscal regenerative approaches in the future.

\section{Meniscal Structure and Biomechanical Properties}

2.1. Meniscal Anatomy. Menisci are a pair of crescent-shaped fibrocartilages located at the corresponding femoral condyles 


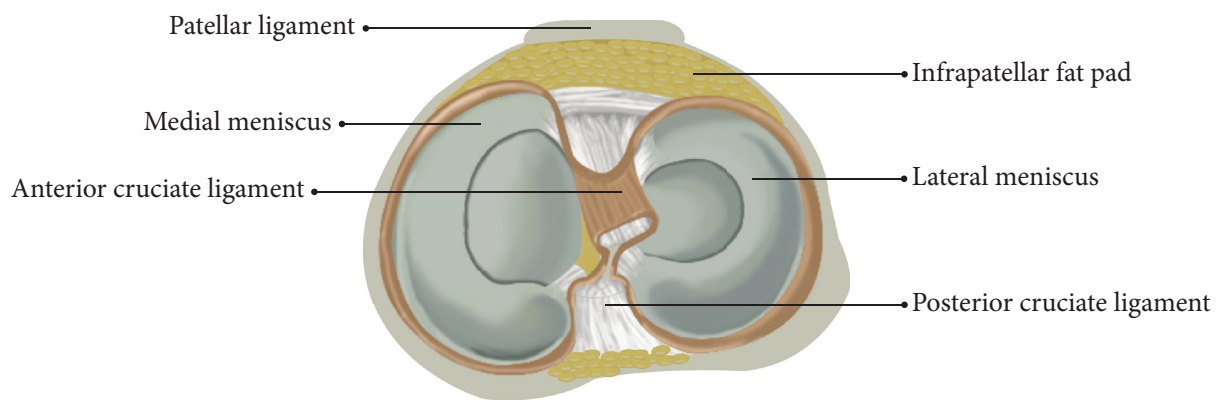

(a)

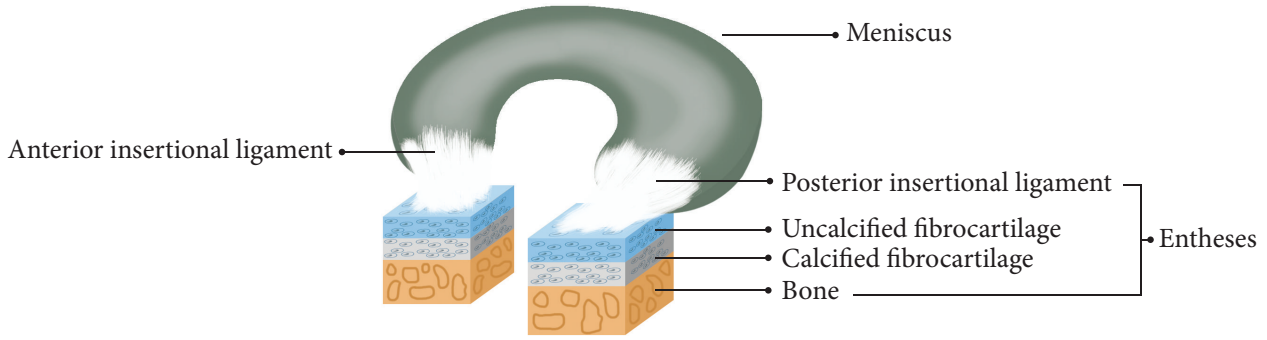

(b)

Figure 1: Top view of the anatomical meniscus (a): lateral meniscus is "O" shaped, whereas the medial meniscus has a " $\mathrm{C}$ " appearance. The meniscal functional unit (b), including the corresponding anterior and posterior ligaments and entheses. Entheses typically contain ligaments, uncalcified fibrocartilage, calcified fibrocartilage, and bone.

and tibial plateau, respectively (Figure 1(a)) [20]. The lateral meniscus covers nearly $80 \%$ of the tibial plateau area, whereas the medial meniscus only covers $\sim 60 \%$ [21]. The geometry of the meniscus adapts well to the corresponding shape of the femoral condyle and tibial plateau. The anterior and posterior insertional ligaments play a critical role in attaching the menisci firmly, and they fix the meniscus to the tibial plateau well [22]. Blood vessels and nerves from the surrounding joint capsule and synovial tissues merely penetrate $10-25 \%$ of the outside of the adult meniscus. Therefore, the meniscus can be typically classified into three parts according to vascular and nervous distribution: the outer vascular/neural area (red-red zone), the inner entirely avascular/aneural area (white-white zone), and the junctional area (red-white zone) between the former two regions. The white-white zone does not self-heal well when damaged [23].

2.2. Meniscal Composition and Cell Characteristics. The meniscus has a highly heterogeneous extracellular matrix (ECM) and cell distribution [24-26]. Meniscal ECM components are more complex than those of articular cartilage. Cartilage has a homogeneous ECM composition, mainly comprised of water (70-80\%), collagen (50-75\%), and glycosaminoglycans (GAGs) (15-30\%) [27]. The distribution of the meniscal ECM is categorized by region. Collagen type I accounts for $>80 \%$ of the composition in the red-red region by dry weight, and the remaining content comprises $<1 \%$, including collagen types II, III, IV, VI, and XVIII [14]. Total collagen content is $70 \%$ of the dry weight in the white-white region, whereas collagen types II and I account for $60 \%$ and $40 \%$, respectively. The specific distribution of meniscal ECM components is shown in Figure 2.
Meniscal cell populations are classified into three types according to the different regions and cell morphology (Figure 2) [28]. The outer one-third of the meniscal area is comprised of fibroblast-like cells, which demonstrate elongated morphology. The inner two-thirds of the meniscal region mainly contain fibrochondrocytes, which are predominantly oval to round in appearance. Fusiform cells are aligned parallel to the meniscal surface in the superficial zone.

2.3. Meniscal Biomechanical Properties. The anatomic geometry of the meniscus is closely associated with its biomechanical properties. The meniscal configuration adapts to the corresponding shapes of the femoral condyles and tibial plateau, which provide a considerable increase in contact area in the knee joint $[29,30]$. Tensile hoop stress is created around the circumference when the knee bears an axial load, and this stress tries to extrude the meniscus out of the knee joint (Figure 3). However, firm attachment at the anterior and posterior insertional ligaments helps prevent extrusion of the meniscus [31, 32]. Thus, intact menisci occupy the corresponding contact area (60\%) between the femoral condyles and the tibial plateau cartilage, which significantly reduces stress and protects the tibial cartilage. In contrast, if the anterior or posterior insertional ligaments or peripheral circumferential collagen fibers rupture [33], the load transmission mechanism changes, which damages the tibial cartilage.

2.4. Meniscal Lesions and Development of Knee OA. Meniscal lesions are closely associated with the development of knee $\mathrm{OA}$, and their relationship is complex [34]. Meniscal lesions 


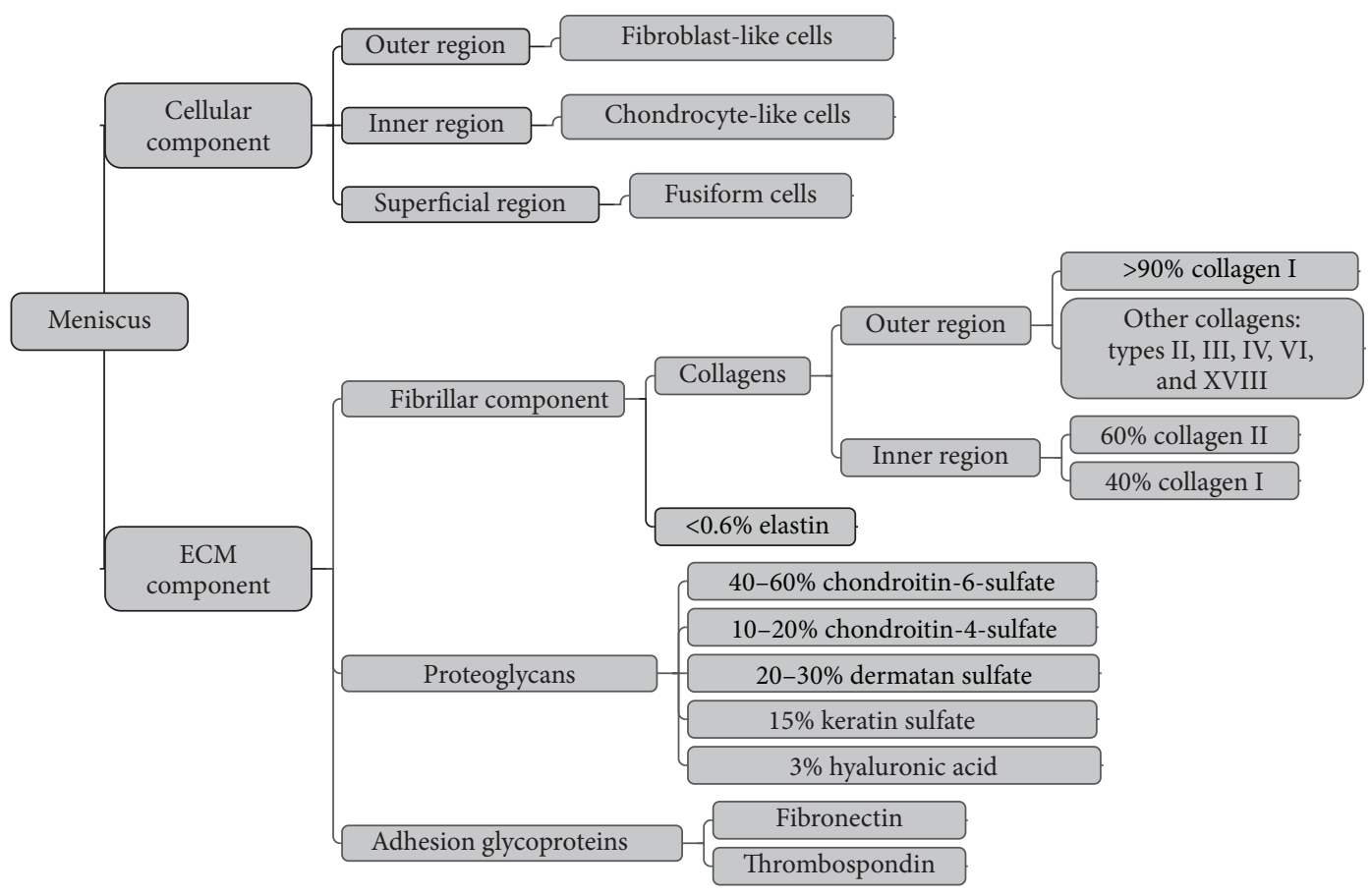

FIGURE 2: The complex composition of the meniscal cellular and meniscal extracellular matrix (ECM) components. The outer region is the outer one-third of the meniscus; the inner region is the inner two-thirds of the meniscus; the superficial region is the surface of the meniscus.
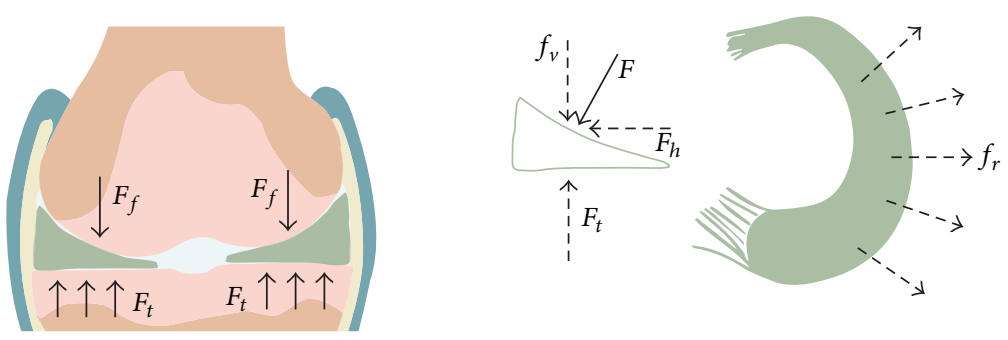

FIGURE 3: Schematic diagram of the meniscus force-bearing mechanism. Meniscal configuration adapts well to the corresponding shape of the femoral condyles and the tibial plateau in the knee joint. The axial load force $(F)$ perpendicular to the meniscus surface and horizontal force $\left(f_{r}\right)$ are created by compressing the femur $\left(F_{f}\right)$. $F$ rebounds due to the tibial upgrade force $\left(F_{t}\right)$, whereas the $f_{r}$ leads to meniscal extrusion radially, which is countered by the pulling force from the anterior and posterior insertional ligaments. Consequently, tensile hoop stress is created along the circumferential directions during axial compression.

can ultimately lead to knee OA, and knee OA also induces meniscal tears; therefore, normally configured menisci are rarely observed in patients with knee OA [35, 36]. An injured meniscus triggers the synovium to release various inflammatory cytokines, which induce degenerative changes in the meniscal matrix. These degenerative changes derived from early stage tears can gradually develop into meniscal extrusions that increase the stress on tibial cartilage and further aggravate the injury [24]. In addition, inflammatory cytokines released into OA joints simultaneously act on the meniscus and cartilage, as they have similar ECM components. Therefore, knee OA induced by other diseases is harmful to the meniscus and triggers similar pathological changes $[25,26,37,38]$. Hence, a natural vicious cycle forms between meniscal lesions and the development of knee OA (Figure 4).
2.5. Classification of Meniscal Lesions and Therapeutic Strategies. Damage to the meniscus is very common in the knee joint. Meniscal lesions are typically categorized into distinct age groups. Meniscal injuries in younger patients $(<40$ years) are usually caused by trauma or congenital meniscal diseases, whereas those in older patients ( $>40$ years) tend to be associated with degenerative tears [39]. In general, all meniscal lesions can be comprehensively classified into eight different types according to Casscells classification (Figure 5) [40]. However, meniscal injuries can simply be classified clinically into peripheral meniscal lesions and avascular meniscal lesions.

Orthopedic surgeons commonly perform a partial meniscectomy in cases of unrepairable or degenerative meniscal injuries [41]. However, this treatment strategy does not prevent the development of knee OA. A partial meniscectomy 


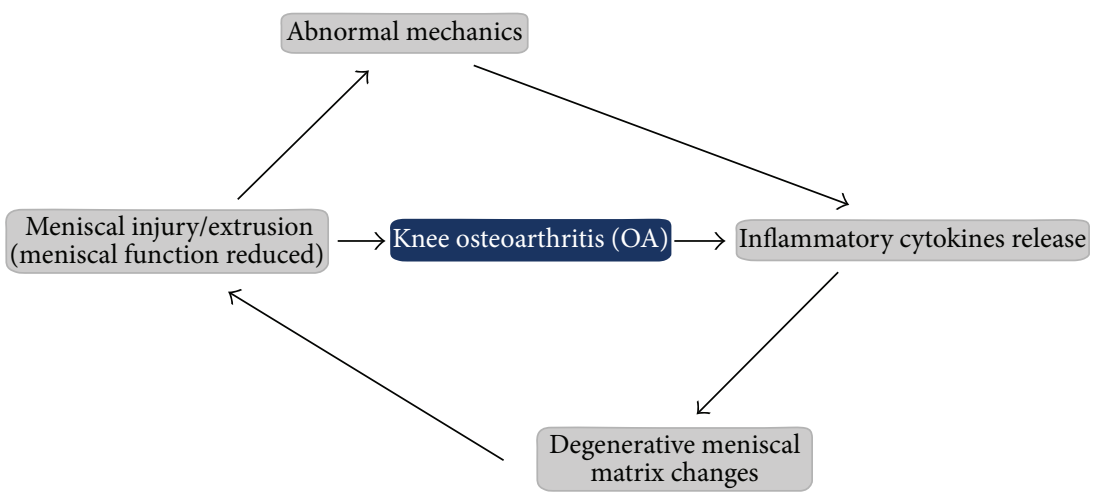

FIGURE 4: The interaction between meniscal injury and knee osteoarthritis (OA). Knee mechanics become abnormal when a meniscus is injured, which leads to increasing stress across adjacent cartilage and subchondral bone. This stress triggers release of inflammatory cytokines, which further impair the meniscal extracellular matrix (ECM) and accelerate the vicious cycle of knee OA. OA of the knee joint also causes release of inflammatory cytokines, repeating the vicious cycle.

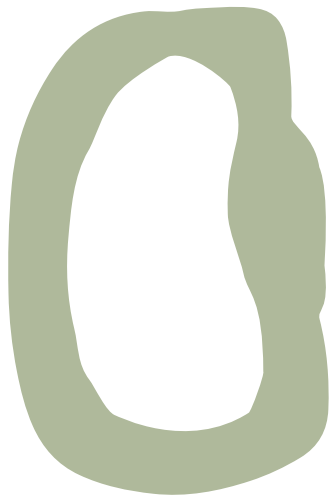

(I) Vertical longitudinal (bucket handle tear)

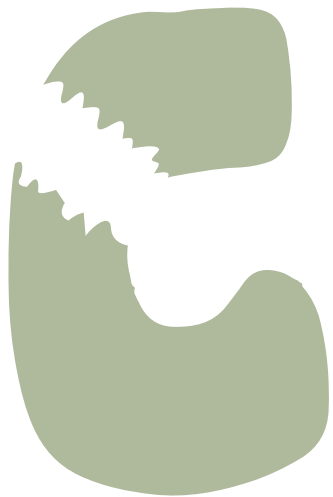

(V) Detachment of meniscal horns

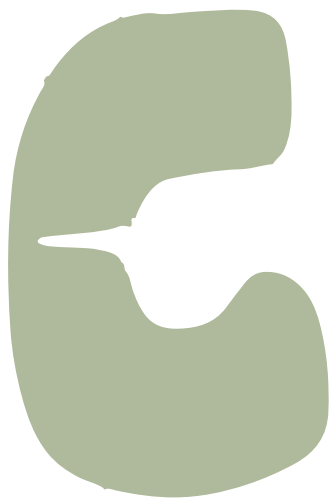

(II) Vertical transverse (radial)

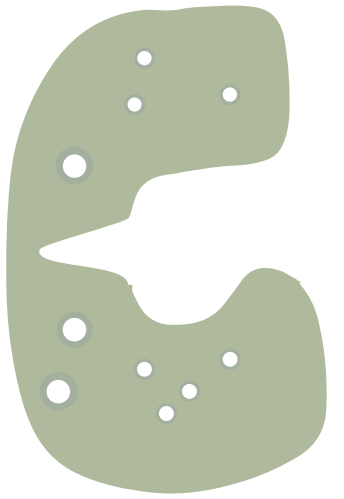

(VI) Complex tear

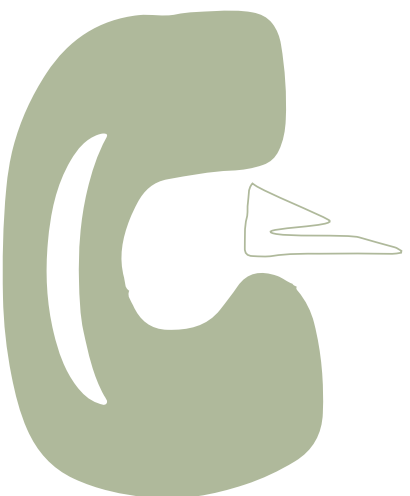

(III) Horizontal tear (cleavage)

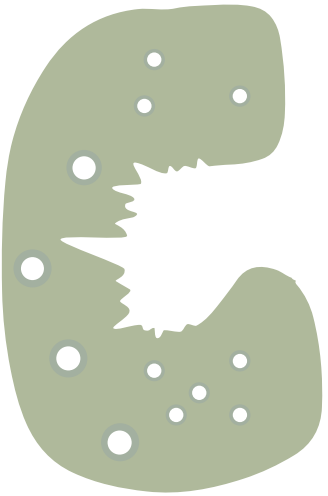

(VII) Degenerative

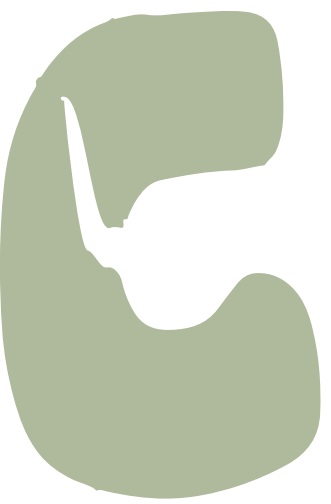

(IV) Oblique tear (flap)

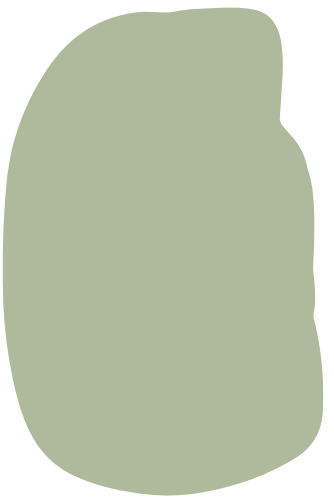

(VIII) Miscellaneous (discoid)

FIGURE 5: Schematic diagram of the eight different types of meniscal lesions according to Casscells classification.

may decrease the contact area between the femoral condyle and tibial platform $[35,36]$. Therefore, meniscal repair and reconstruction techniques have received much attention [42]. Younger patients with repairable injuries, such as longitudinal lesions or injuries in the vascular zone, are generally better candidates for meniscal repair. The types of repair procedures are inside-out, outside-in, all-inside, and repair enhancement. In contrast, an increasing number of reconstruction strategies have been developed to restore meniscal function, including meniscal allografts, small intestinal submucosa (SIS) implants, and autogenous tendon grafts. Milachowski and Wirth performed the first free meniscal allograft transplantation in 1984 [43]. Meniscal allograft transplantation enhances knee function and reduces pain 
significantly in relatively young patients after a short followup $[44,45]$. However, whether meniscal allografts provide long-term protective benefits to the cartilage remains debatable, as meniscal allograft transplantations can increase the risk of disease transmission, decrease material properties, and the allografts can shrink [46]. SIS and autogenous tendon grafts have not obtained satisfactory results $[47,48]$.

\section{Advances in Meniscal Scaffolds}

3.1. The Bioabsorbable Synthetic Polymer Scaffold (Table 1). Bioabsorbable synthetic polymers, such as polyurethane (PU), polyglycolic acid (PGA), polylactic acid, and poly ( $\varepsilon$ caprolactone) (PCL), are widely used and have played a key role creating meniscal scaffolds [49]. These polymers provide several advantages, such as versatility, satisfactory biomechanical properties, and access to a nearly endless supply. However, some disadvantages of synthetic polymers include their hydrophobic properties, lack of bioactivity, and production of aseptic inflammation or an immune response.

Koller et al. attempted to enhance the bioactivity of synthetic scaffolds by adding polyethylene terephthalate (PET) to hyaluronic acid/PCL scaffolds [62]. Their results demonstrated that scaffolds with PET express more type II collagen mRNA and secrete more GAGs than those without PET. It is well known that native meniscal collagen fibers align circumferentially [11]. Baker and Mauck developed aligned (AL) scaffolds by electrospinning [63]. Cells in the AL group displayed an AL morphology, whereas those in the nonaligned (NA) group took on a polygonal shape. The biomechanical properties increased in the AL group, as compared to those of the NA scaffolds. Thus, AL scaffolds directed cell growth and enhanced biomechanical capacity. Similarly, Fisher et al. used a modified electrospinning approach to produce circumferentially AL scaffolds [64], and the results showed that seeding juvenile bovine mesenchymal stem cells (MSCs) in the scaffolds resulted in circumferential cellular alignment, similar to that seen in the native meniscus.

Koller et al. used PGA reinforced by bonding with PLGA $(75: 25)$ to fabricate a meniscus-like scaffold [62]. Allogenic meniscal cells were seeded into the scaffolds in vitro for 1 week to replace the medial meniscus in rabbits. The staining results showed that the regenerated neomenisci were similar to the native meniscus; however, the neomenisci did not prevent the tibial articular cartilage from degenerating, and cartilage degeneration was less severe in the cell-seeded group than that in the nonseeded group. Chiari et al. used hyaluronic acid and PCL in scaffolds to repair total and partial meniscal defects in sheep [65]. These scaffolds were not seeded with cells before implantation. The implant retained its morphology and remained in position for 6 weeks. The histological results showed that the implants and native menisci were integrated, and a large number of blood vessels formed to firmly bond the capsule, which was covered by synovial-like tissue. However, body weight led to extrusion and unavoidable degeneration of the cartilage in both the total and partial transplantation groups but cartilage degeneration was slightly less than that in the empty control group.
The novel biodegradable Actifit implant (Orteq Sports Medicine, London, UK) is an acellular meniscal scaffold composed of PU (20\%) and PCL (80\%) [66]. The interconnected pore structure enhances vessel in-growth and regeneration of the meniscus from the meniscal wall. A study using Actifit during partial meniscectomy repair in 13 skeletally mature sheep revealed regenerated tissue penetration 6-12 months after surgery [58]. Actifit has also been applied clinically to treat partial meniscal lesions. As results, dynamic contrastenhanced magnetic resonance imaging (DCE-MRI) showed successful tissue growth into the scaffold after 3 months in 35 of 43 (81.4\%) patients [67]. In contrast, 43 of 44 (97.7\%) patients revealed integration with the native meniscus 12 months after surgery, and the histological results showed continuous tissue regeneration. Baynat et al. demonstrated that normal chondrocytes and fibrochondrocytes of 18 patients penetrated into the substitute 1 year post-Actifit implantation [61]. All patients were restored to their daily activities, and nine returned to their previous sporting activity level 2 years after surgery. Moreover, MRI showed no damage to the substitute or degeneration of adjacent cartilage.

\section{Absorbable Scaffolds Derived from Biological Components (Table 2)}

Absorbable scaffolds derived from biological components are very promising. They can be classified as ECM-related scaffolds and biological scaffolds.

Stone et al. reported on copolymeric collagen-based scaffolds derived from bovine Achilles tendon to repair subtotal meniscectomy in dogs without seeding cells [79]. The implanted group showed substantial meniscus-like regeneration in 15 of 24 (63\%) joints, compared to 3 of 12 (25\%) regenerated menisci in nonimplanted control joints. In contrast, joint gross appearance scores and India ink test scores demonstrated no significant differences. Based on these results, the collagen meniscus implant (CMI) was applied without seeding cells in a multicenter clinical trial [80]. CMIs were implanted in patients with chronic and acute meniscal injuries and compared with a partial meniscectomy group. Biopsies 1 year after implantation showed that some meniscal-like tissues had regenerated and integrated well with the host meniscal rim in the chronic group. These patients regained significantly more mobility and required fewer reoperations than those in the control group. The authors concluded that the improved clinical outcomes could be a result of regenerated meniscal-like tissues. However, CMIs did not improve the clinical outcomes of patients with acute meniscal injuries.

Monllau et al. reported the clinical outcomes of implanting CMIs after a minimum 10-year follow-up [74]. Twentyfive of their patients with a CMI substitute reported remarkable pain relief and functional improvement without any degenerative knee joint diseases in most cases. However, this was a nonrandomized trial and lacked a control group, which restricts the credibility of the results. Zaffagnini et al. conducted a cohort study during a minimum 10-year follow-up [75] and obtained similar results to the former 


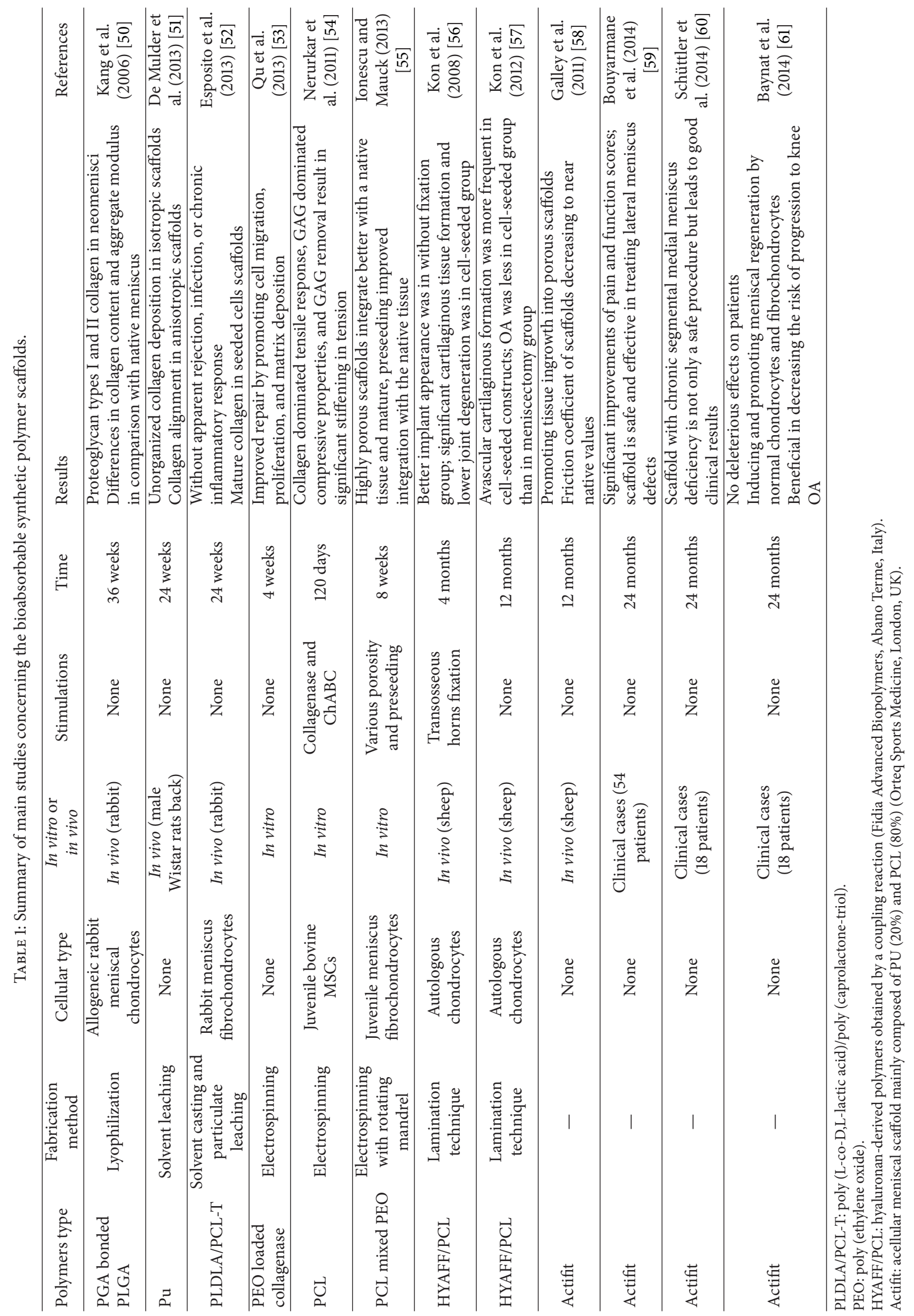




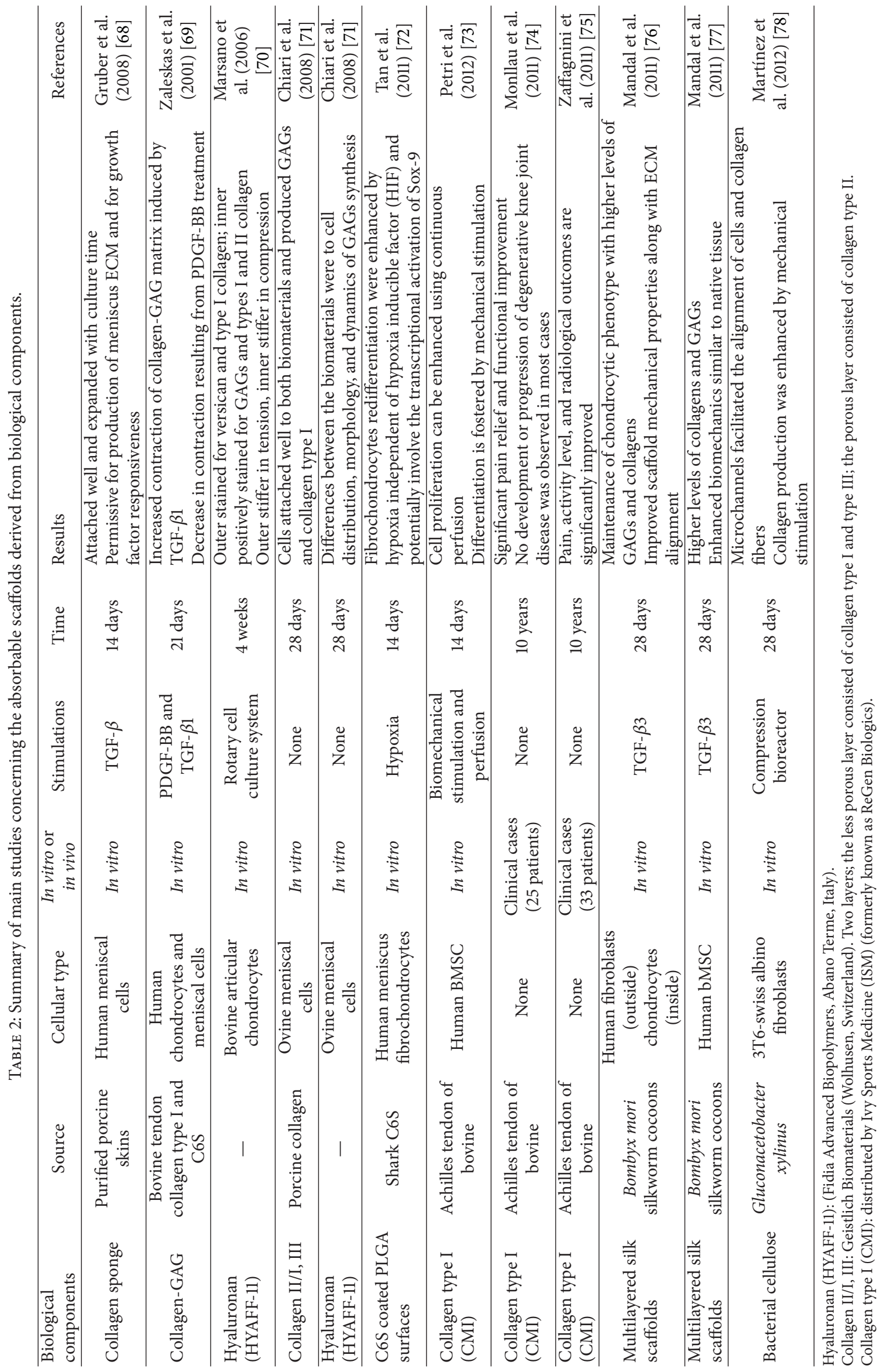


case report. Long-term randomized controlled trials on larger populations must be carried to confirm the benefits of CMI substitution.

Tan et al. found that dedifferentiation of rat or human meniscal fibrochondrocytes can be reversed using chondroitin-6-sulfate- (C6S-) coated rather than collagen I/II surfaces during expansion of the monolayer [72, 81]. They demonstrated upregulation of collagen II and aggrecan gene expression, as well as proteoglycan production. Those authors fabricated a C6S scaffold and explored the three-dimensional (3D) conditions and oxygen tension effect on a cell-C6S scaffold construct. The results showed that the $3 \mathrm{D}$ cultures under hypoxic conditions strengthen fibrochondrocyte redifferentiation capacity.

Silks are a group of fibrous proteins [82] widely used in tissue engineering for chondrogenesis, osteogenesis, ligament engineering, and other aspects. Silks possess superior biomechanical capabilities, versatile processability, and good biocompatibility and controlled degradability [83]. Mandal et al. used silk fibroin from Bombyx mori silkworm cocoons to recapitulate a multilayered, multiporous scaffold that mimicked native meniscal architecture and morphology [76]. Human primary fibroblasts were seeded into the outside of the scaffold, and human primary chondrocytes were seeded into the inside to duplicate normal meniscal cell distributions. The results showed that the constructs increased cellularity and ECM content under chondrogenic culture conditions. In addition, the compressive modulus and tensile modulus increased with time; however, they remained inferior to those of the native meniscus. Shortly thereafter, the same authors used human bone marrow stem cells to construct tissue-engineered menisci with this multilayered scaffold and obtained similar results [77].

Bacterial cellulose (BC) is a polysaccharide synthesized by the Gluconacetobacter xylinus bacterium [78]. BC has numerous advantages in tissue engineering, such as superior biomechanical capacity, high hygroscopicity and crystallinity, and good biocompatibility. BC has been applied to blood, vessel, cartilage, and bone tissue engineering, as well as to treat burns [84]. Bodin et al. compared the biomechanical properties of $\mathrm{BC}$ gel to collagen material and a pig meniscus [85]. The compression modulus of the $\mathrm{BC}$ gel at $10 \%$ strain $(1.8 \mathrm{kPa})$ was five times better than that of the collagen meniscal implant $(0.23 \mathrm{kPa})$; however, it was inferior to the native pig meniscus $(21 \mathrm{kPa})$. In another study, Martínez et al. fabricated a microchanneled BC scaffold seeded with 3T6 mouse fibroblasts and compared dynamic compression to that of a static culture [78]. The results showed that the microchannel structure directed the growth of 3T6 fibroblasts and secreted AL collagen fibers. Similarly, dynamic stimulation improved collagen production.

\section{Hydrogel Scaffolds}

Hydrogels have been used as meniscal scaffolds due to their noncytotoxic and insoluble features. Hydrogels are made of poly $\mathrm{N}$-isopropyl acrylamide or alginate [14]. These materials can absorb large quantities of water (>90\%), which determines their physical properties but they also exhibit great versatility, which can be beneficial for evenly mixing seed cells, loading growth factors, or creating appropriate morphology [86]. However, hydrogel scaffolds have poor tensile capacity and bioactivity.

Polyvinyl alcohol-hydrogel (PVA-H) has excellent viscoelastic properties and biocompatibility. Kobayashi et al. developed PVA-H artificial menisci to replace defective menisci. Mechanical tests confirmed that the PVA-H artificial meniscus has similar mechanical properties to those of the native meniscus [87]. A PVA-H artificial meniscus implantation group revealed normal articular cartilage conditions $1,1.5$, and 2 years after surgery in rabbit studies [88-90], and no wear or disruption of the PVA-H artificial menisci was observed. However, knee OA was detected after 1 year and continued to progress in the meniscectomy group. These results suggest that PVA-H artificial menisci are as competent as the native meniscus and have potential future clinical applications.

Grogan et al. constructed a 3D methacrylated gelatin (GelMA) meniscal scaffold using projection stereolithography that mimicked native collagen alignment [91]. The authors chose human avascular-zone meniscal cells to seed into the scaffolds for 2 weeks with a chondrogenic culture and then implanted the scaffolds into defective menisci. The 3-week postoperative results confirmed that the GelMA scaffolds were nontoxic and directed cell-aligned growth. Sarem et al. fabricated macroporous multilayered gelatin (G)/chitosan (Cs) scaffolds [92, 93]. Cs in conjunction with $\mathrm{G}$ not only enhances the bioactivity of $\mathrm{Cs}$ but also improves water retention and oxygen and nutrient transfer because of the hydrophilicity of G [94]. Ishida et al. investigated platelet-rich plasma (PRP) combined with gelatin hydrogel scaffolds to enhance meniscal regeneration [95]. PRP can be prepared easily from a patient's blood by centrifugation and is a rich source of growth factors, such as platelet-derived growth factor, insulin-like growth factor1 , and transforming growth factor $\beta$-I (TGF $\beta$-I) [96]. The findings showed that PRP enhances regeneration of a defective avascular meniscus. Similarly, Simson et al. tested bone marrow (BM) and chondroitin sulfate (CS) to improve the regenerative capacity of hydrogel scaffolds [97]. Their results showed that BM improves fibrochondrocyte viability, proliferation, and migration, whereas CS enhances adhesive strength and matrix production. In another study, Ballyns et al. constructed an anatomically shaped meniscus using alginate and investigated the interaction between media-mixed and engineered tissue [98]. The results confirmed that adequate mixing improves biomechanical properties and the accumulation of matrix in the engineered constructs.

\section{Decellularized Meniscal Scaffolds}

Decellularized meniscal scaffolds not only provide a suitable microenvironment for cells but also preserve appropriate meniscal geometry. However, some challenges should be addressed to obtain ideal meniscal scaffolds. 
It is difficult for seed cells to evenly penetrate a decellularized meniscus. A high concentration of bone morphogenetic protein-2 (BMP-2), a member of the TGF- $\beta$ superfamily, stimulates MSC differentiation and can affect cell migration. Minehara et al. used recombinant human bone morphogenetic protein-2 (rhBMP-2) loading in solvent-preserved human menisci to induce migration of chondrocytes into decellularized menisci [99]. The results showed that rhBMP-2 induces migration of chondrocytes and improves proteoglycan production in vitro. The seed cell distribution challenge could be addressed in vitro by taking full advantage of these kinds of exogenous chemokines.

Sandmann et al. used sodium dodecyl sulfate (SDS) as the main ingredient to decellularize human menisci [100], and the results showed that this method retains collagen structure. The results of a biomechanical assessment using a repetitive ball indentation test (stiffness, $\mathrm{N} / \mathrm{mm}$; residual force, $\mathrm{N}$; relative compression force, $\mathrm{N}$ ) on the processed tissue were similar to those of the intact meniscus, and the histological results showed no residual cells. Stapleton et al. attempted a complicated decellularized procedure consisting of freeze-thaw cycles, SDS, and disinfection using peracetic acid [101] to obtain decellularized scaffolds. As a result, the scaffolds demonstrated well-preserved structural proteins and biomechanical properties and were not cytotoxic.

Maier et al. used a self-developed enzymatic process to treat ovine menisci [102]. Their results suggested that native cells and immunogenic proteins (MHC-1/MHC-2) are completely removed while retaining significant biomechanical properties. Stabile et al. applied concomitant decellularization and oxidation processes to improve porosity [103]. Porosity of the decellularized scaffolds increased to some extent, and the scaffolds were not cytotoxic. In addition, Azhim et al. used a neoteric sonication decellularization system to produce decellularized bovine meniscal scaffolds [104]. These scaffolds had good biomechanical properties, similar to those of native meniscus, and the immunogenic cell components were removed. Nevertheless, the sonication treatment significantly changed the native ECM components and collagen fiber arrangement.

\section{Future Prospects for Meniscal Regeneration}

Future tissue-engineered meniscus strategies should focus on constructing an entire functional unit to maintain knee joint homoeostasis. Constructing an inferior biomechanical meniscus prevents proper knee joint function. Messner and Gao used menisci and their insertions into bone (entheses) to represent a functional unit [20], containing a meniscal body with anterior and posterior ligaments and entheses (Figure 1(b)). This unit may suggest the future development of a tissue-engineered meniscus.

Three-dimensional printing could benefit the development of ideal meniscal scaffolds with biomimetic structure and a beneficial microenvironment for cell growth. Lee et al. fabricated 3D-printed novel human meniscal scaffolds that recapitulated principal collagen alignment using PCL loaded with human connective tissue growth factor and TGF- $\beta 3$ [105].
Meniscal anatomical requirements for orthopedic applications could be addressed by advances in imaging. Ballyns et al. generated a tissue-engineered meniscus for the first time based on meniscal anatomic geometry using microcomputed tomography and MRI [106]. Thus, a perfect combination of the meniscal unit, 3D printing, and medical imaging technology could direct future development of meniscal tissue engineering to achieve knee joint homoeostasis [107].

\section{Conclusions}

The study of scaffolds is the basis for meniscal tissue engineering. Nevertheless, a concerted effort must be made to explore other options, including seed cells and appropriate biological and biomechanical stimulation. It is insufficient to prepare scaffolds that are merely biomimetic to meniscal composition and structure. The key issue is how to obtain the excellent biomechanical function of the native meniscus. Future engineered menisci should combine these advantages to achieve an individualized tissue similar to that of the native meniscus.

\section{Abbreviations}

$\begin{array}{ll}\text { AL: } & \text { Aligned } \\ \text { BC: } & \text { Bacterial cellulose } \\ \text { BM: } & \text { Bone marrow } \\ \text { Cs: } & \text { Chitosan } \\ \text { C6S: } & \text { Chondroitin-6-sulfate } \\ \text { CS: } & \text { Chondroitin sulfate } \\ \text { CTGF: } & \text { Connective tissue growth factor } \\ \text { CMI: } & \text { Collagen meniscus implant } \\ \text { DCE-MRI: } & \text { Dynamic contrast-enhanced magnetic } \\ & \text { resonance imaging } \\ \text { ECM: } & \text { Extracellular matrix } \\ \text { GAGs: } & \text { Glycosaminoglycans } \\ \text { HIF: } & \text { Hypoxia-inducible factor } \\ \text { IGF-I: } & \text { Insulin-like growth factor } \\ \text { MHC 1/MHC 2: } & \text { Major histocompability complex } \\ & \text { 1/Major histocompability complex } 2 \\ \text { MRI: } & \text { Magnetic resonance imaging } \\ \text { MSCs: } & \text { Mesenchymal stem cells } \\ \text { GelMA: } & \text { Methacrylated gelatin } \\ \mu \text { CT: } & \text { Microcomputed tomography } \\ \text { G: } & \text { Gelatin } \\ \text { NA: } & \text { Nonaligned } \\ \text { OA: } & \text { Osteoarthritis } \\ \text { PDGF: } & \text { Platelet-derived growth factor } \\ \text { PRP: } & \text { Platelet-rich plasma } \\ \text { PET: } & \text { Polyethylene terephthalate } \\ \text { PGA: } & \text { Polyglycolic acid } \\ \text { PLA: } & \text { Polylactic acid } \\ \text { PLGA: } & \text { Polylactic co-glycolic acid } \\ \text { PCL: } & \text { Poly ( } \varepsilon \text {-caprolactone) } \\ \text { PU: } & \text { Polyurethane } \\ \text { SDS: } & \text { Sodium dodecyl sulfate } \\ \text { SIS: } & \text { Transforming growth factor } \beta \text {-I. } \\ \text { TGF } \beta \text {-I: } & \end{array}$




\section{Conflict of Interests}

The authors declare that there is no conflict of interests regarding the publication of this paper.

\section{Authors' Contribution}

All authors were involved in drafting the paper, and all authors approved the final version to be published.

\section{Acknowledgments}

This work was funded by the Beijing Metropolis Beijing Nova Program (2011115), the National Natural Science Foundation of China (General Program) (31170946), the National Natural Science Foundation of China (Youth Program) (31100696), the National Natural Science Foundation of China (81472092), the National High Technology Research and Development Program of China (2012AA020502), the People's Liberation Army 12th Five-Year Plan Period (Key Program) (BWS11J025), the National Basic Research Program of China (973 Program) (2012CB518106), the National Natural Science Foundation of China (Key Program) (21134004), and the New Drug Creation of the Special Ministry of Science and Technology.

\section{References}

[1] C. Scotti, M. T. Hirschmann, P. Antinolfi, I. Martin, and G. M. Peretti, "Meniscus repair and regeneration: review on current methods and research potential," European Cells \& Materials, vol. 26, pp. 150-170, 2013.

[2] B. E. Baker, A. C. Peckham, F. Pupparo, and J. C. Sanborn, "Review of meniscal injury and associated sports," The American Journal of Sports Medicine, vol. 13, no. 1, pp. 1-4, 1985.

[3] A. Hede, D. B. Jensen, P. Blyme, and S. Sonne-Holm, "Epidemiology of meniscal lesions in the knee: 1,215 open operations in Copenhagen 1982-84," Acta Orthopaedica, vol. 61, no. 5, pp. 435-437, 1990.

[4] T. Annandale, "Excision of the internal semilunar cartilage, resulting in perfect restoration of the joint-movements," The British Medical Journal, vol. 1, no. 1467, pp. 291-292, 1889.

[5] M. W. Gear, "The late results of meniscectomy," The British Journal of Surgery, vol. 54, no. 4, pp. 270-272, 1967.

[6] R. J. Johnson, D. B. Kettelkamp, W. Clark, and P. Leaverton, "Factors effecting late results after meniscectomy," The Journal of Bone \& Joint Surgery-American Volume, vol. 56, no. 4, pp. 719-729, 1974.

[7] P. R. Allen, R. A. Denham, and A. V. Swan, "Late degenerative changes after meniscectomy. Factors affecting the knee after operation," The Journal of Bone and Joint Surgery-British Volume, vol. 66, no. 5, pp. 666-671, 1984.

[8] M. Englund, E. M. Roos, H. P. Roos, and L. S. Lohmander, "Patient-relevant outcomes fourteen years after meniscectomy: influence of type of meniscal tear and size of resection," Rheumatology, vol. 40, no. 6, pp. 631-639, 2001.

[9] L. S. Lohmander, P. M. Englund, L. L. Dahl, and E. M. Roos, "The long-term consequence of anterior cruciate ligament and meniscus injuries: osteoarthritis," The American Journal of Sports Medicine, vol. 35, no. 10, pp. 1756-1769, 2007.
[10] H. U. Cameron and I. Macnab, “The structure of the meniscus of the human knee joint," Clinical Orthopaedics and Related Research, vol. 89, pp. 215-219, 1972.

[11] A. P. Newman, D. R. Anderson, A. U. Daniels, and M. C. Dales, "Mechanics of the healed meniscus in a canine model," The American Journal of Sports Medicine, vol. 17, no. 2, pp. 164-175, 1989.

[12] W. Zhu, K. Y. Chern, and V. C. Mow, "Anisotropic viscoelastic shear properties of bovine meniscus," Clinical Orthopaedics and Related Research, no. 306, pp. 34-45, 1994.

[13] M. Tissakht, A. M. Ahmed, and K. C. Chan, "Calculated stress-shielding in the distal femur after total knee replacement corresponds to the reported location of bone loss," Journal of Orthopaedic Research, vol. 14, no. 5, pp. 778-785, 1996.

[14] E. A. Makris, P. Hadidi, and K. A. Athanasiou, "The knee meniscus: structure-function, pathophysiology, current repair techniques, and prospects for regeneration," Biomaterials, vol. 32, no. 30, pp. 7411-7431, 2011.

[15] F. N. Ghadially, I. Thomas, N. Yong, and J. M. A. Lalonde, "Ultrastructure of rabbit semilunar cartilages," Journal of Anatomy, vol. 125, no. 3, pp. 499-517, 1978.

[16] T. Kusayama, C. D. Harner, G. J. Carlin, J. W. Xerogeanes, and B. A. Smith, "Anatomical and biomechanical characteristics of human meniscofemoral ligaments," Knee Surgery, Sports Traumatology, Arthroscopy, vol. 2, no. 4, pp. 234-237, 1994.

[17] D. Kohn and B. Moreno, "Meniscus insertion anatomy as a basis for meniscus replacement: a morphological cadaveric study," Arthroscopy, vol. 11, no. 1, pp. 96-103, 1995.

[18] B. Shaffer, S. Kennedy, J. Klimkiewicz, and L. Yao, "Preoperative sizing of meniscal allografts in meniscus transplantation," The American Journal of Sports Medicine, vol. 28, no. 4, pp. 524-533, 2000.

[19] I. D. McDermott, F. Sharifi, A. M. J. Bull, C. M. Gupte, R. W. Thomas, and A. A. Amis, "An anatomical study of meniscal allograft sizing," Knee Surgery, Sports Traumatology, Arthroscopy, vol. 12, no. 2, pp. 130-135, 2004.

[20] K. Messner and J. Gao, "The menisci of the knee joint. Anatomical and functional characteristics, and a rationale for clinical treatment," Journal of Anatomy, vol. 193, no. 2, pp. 161178, 1998.

[21] C. R. Clark and J. A. Ogden, "Development of the menisci of the human knee joint. Morphological changes and their potential role in childhood meniscal injury," The Journal of Bone \& Joint Surgery-American Volume, vol. 65, no. 4, pp. 538-547, 1983.

[22] D. F. Villegas and T. L. H. Donahue, "Collagen morphology in human meniscal attachments: a SEM study," Connective Tissue Research, vol. 51, no. 5, pp. 327-336, 2010.

[23] S. P. Arnoczky and R. F. Warren, "Microvasculature of the human meniscus," The American Journal of Sports Medicine, vol. 10, no. 2, pp. 90-95, 1982.

[24] M. Englund, A. Guermazi, and L. S. Lohmander, "The meniscus in knee osteoarthritis," Rheumatic Disease Clinics of North America, vol. 35, no. 3, pp. 579-590, 2009.

[25] H. Roos, T. Adalberth, L. Dahlberg, and L. S. Lohmander, "Osteoarthritis of the knee after injury to the anterior cruciate ligament or meniscus: the influence of time and age," Osteoarthritis and Cartilage, vol. 3, no. 4, pp. 261-267, 1995.

[26] M. Englund, A. Guermazi, and S. L. Lohmander, "The role of the meniscus in knee osteoarthritis: a cause or consequence?" Radiologic Clinics of North America, vol. 47, no. 4, pp. 703-712, 2009. 
[27] D. J. Huey, J. C. Hu, and K. A. Athanasiou, "Unlike bone, cartilage regeneration remains elusive," Science, vol. 338, no. 6109, pp. 917-921, 2012.

[28] N. J. Gunja and K. A. Athanasiou, "Passage and reversal effects on gene expression of bovine meniscal fibrochondrocytes," Arthritis Research \& Therapy, vol. 9, article R93, 2007.

[29] D. B. Kettelkamp and A. W. Jacobs, "Tibiofemoral contact area-determination and implications," The Journal of Bone \& Joint Surgery Series A, vol. 54, no. 2, pp. 349-356, 1972.

[30] P. S. Walker and M. J. Erkman, "The role of the menisci in force transmission across the knee," Clinical Orthopaedics and Related Research, vol. 109, pp. 184-192, 1975.

[31] J. Gao, G. Oqvist, and K. Messner, "The attachments of the rabbit medial meniscus. A morphological investigation using image analysis and immunohistochemistry," Journal of Anatomy, vol. 185, part 3, pp. 663-667, 1994.

[32] J. Gao and K. Messner, "Natural healing of anterior and posterior attachments of the rabbit meniscus," Clinical Orthopaedics and Related Research, no. 328, pp. 276-284, 1996.

[33] G. A. Jr. Paletta, T. Manning, E. Snell, R. Parker, and J. Bergfeld, "The effect of allograft meniscal replacement on intraarticular contact area and pressures in the human knee. A biomechanical study," The American Journal of Sports Medicine, vol. 25, no. 5, pp. 692-698, 1997.

[34] D. J. Hunter, Y. Q. Zhang, J. B. Niu et al., "The association of meniscal pathologic changes with cartilage loss in symptomatic knee osteoarthritis," Arthritis and Rheumatism, vol. 54, no. 3, pp. 795-801, 2006.

[35] T. Bhattacharyya, D. Gale, P. Dewire et al., "The clinical importance of meniscal tears demonstrated by magnetic resonance imaging in osteoarthritis of the knee," The Journal of Bone \& Joint Surgery-American Volume, vol. 85, no. 1, pp. 4-9, 2003.

[36] M. Englund, A. Guermazi, D. Gale et al., "Incidental meniscal findings on knee MRI in middle-aged and elderly persons," The New England Journal of Medicine, vol. 359, no. 11, pp. 1108-1115, 2008.

[37] M. Englund, F. W. Roemer, D. Hayashi, M. D. Crema, and A. Guermazi, "Meniscus pathology, osteoarthritis and the treatment controversy," Nature Reviews Rheumatology, vol. 8, no. 7, pp. 412-419, 2012.

[38] D. T. Felson, "Osteoarthritis as a disease of mechanics," Osteoarthritis and Cartilage, vol. 21, no. 1, pp. 10-15, 2013.

[39] I. McDermott, "Meniscal tears, repairs and replacement: their relevance to osteoarthritis of the knee," British Journal of Sports Medicine, vol. 45, no. 4, pp. 292-297, 2011.

[40] R. Burnett and R. L. Allum, "Relevance of history of injury to the diagnosis of meniscal tears," Annals of the Royal College of Surgeons of England, vol. 75, no. 4, pp. 229-230, 1993.

[41] K. H. Yoon and K. H. Park, "Meniscal repair," Knee Surgery \& Related Research, vol. 26, pp. 68-76, 2014.

[42] G. J. Jarit and J. A. Bosco III, "Meniscal repair and reconstruction," Bulletin of the NYU Hospital for Joint Diseases, vol. 68, no. 2, pp. 84-90, 2010.

[43] G. Peters and C. J. Wirth, "The current state of meniscal allograft transplantation and replacement," The Knee, vol. 10, no. 1, pp. 19-31, 2003.

[44] J. P. Hommen, G. R. Applegate, and W. Del Pizzo, "Meniscus allograft transplantation: ten-year results of cryopreserved allografts," Arthroscopy, vol. 23, no. 4, pp. 388-393, 2007.

[45] R. J. P. van der Wal, B. J. W. Thomassen, and E. R. A. van Arkel, "Long-term clinical outcome of open meniscal allograft transplantation," American Journal of Sports Medicine, vol. 37, no. 11, pp. 2134-2139, 2009.

[46] G. Samitier, E. Alentorn-Geli, D. C. Taylor et al., "Meniscal allograft transplantation. Part 1: systematic review of graft biology, graft shrinkage, graft extrusion, graft sizing, and graft fixation," Knee Surgery, Sports Traumatology, Arthroscopy, vol. 23, no. 1, pp. 310-322, 2015.

[47] L. L. Johnson and J. A. Feagin Jr., "Autogenous tendon graft substitution for absent knee joint meniscus: a pilot study," Arthroscopy, vol. 16, no. 2, pp. 191-196, 2000.

[48] J. L. Cook, D. B. Fox, P. Malaviya et al., "Long-term outcome for large meniscal defects treated with small intestinal submucosa in a dog model," The American Journal of Sports Medicine, vol. 34, no. 1, pp. 32-42, 2006.

[49] P. A. Gunatillake, R. Adhikari, and N. Gadegaard, "Biodegradable synthetic polymers for tissue engineering," European Cells \& Materials, vol. 5, pp. 1-16, 2003.

[50] S.-W. Kang, S.-M. Son, J.-S. Lee et al., "Regeneration of whole meniscus using meniscal cells and polymer scaffolds in a rabbit total meniscectomy model," Journal of Biomedical Materials Research Part A, vol. 78, no. 3, pp. 659-671, 2006.

[51] E. L. W. De Mulder, G. Hannink, N. Verdonschot, and P. Buma, "Effect of polyurethane scaffold architecture on ingrowth speed and collagen orientation in a subcutaneous rat pocket model," Biomedical Materials, vol. 8, no. 2, Article ID 025004, 2013.

[52] A. R. Esposito, M. Moda, S. M. Cattani et al., "PLDLA/PCLT scaffold for meniscus tissue engineering," BioResearch Open Access, vol. 2, pp. 138-147, 2013.

[53] F. Qu, J.-M. G. Lin, J. L. Esterhai, M. B. Fisher, and R. L. Mauck, "Biomaterial-mediated delivery of degradative enzymes to improve meniscus integration and repair," Acta Biomaterialia, vol. 9, no. 5, pp. 6393-6402, 2013.

[54] N. L. Nerurkar, W. Han, R. L. Mauck, and D. M. Elliott, "Homologous structure-function relationships between native fibrocartilage and tissue engineered from MSC-seeded nanofibrous scaffolds," Biomaterials, vol. 32, no. 2, pp. 461-468, 2011.

[55] L. C. Ionescu and R. L. Mauck, "Porosity and cell preseeding influence electrospun scaffold maturation and meniscus integration in vitro," Tissue Engineering, Part A, vol. 19, no. 3-4, pp. 538-547, 2013.

[56] E. Kon, C. Chiari, M. Marcacci et al., "Tissue engineering for total meniscal substitution: animal study in sheep model," Tissue Engineering_Part A, vol. 14, no. 6, pp. 1067-1080, 2008.

[57] E. Kon, G. Filardo, M. Tschon et al., "Tissue engineering for total meniscal substitution: animal study in sheep model-results at 12 months," Tissue Engineering - Part A, vol. 18, no. 15-16, pp. 1573-1582, 2012.

[58] N. K. Galley, J. P. Gleghorn, S. Rodeo, R. F. Warren, S. A. Maher, and L. J. Bonassar, "Frictional properties of the meniscus improve after scaffold-augmented repair of partial meniscectomy: a pilot study," Clinical Orthopaedics and Related Research, vol. 469, no. 10, pp. 2817-2823, 2011.

[59] H. Bouyarmane, P. Beaufils, N. Pujol et al., "Polyurethane scaffold in lateral meniscus segmental defects: clinical outcomes at 24 months follow-up," Orthopaedics \& Traumatology: Surgery \& Research, vol. 100, no. 1, pp. 153-157, 2014.

[60] K. F. Schüttler, S. Pöttgen, A. Getgood et al., "Improvement in outcomes after implantation of a novel polyurethane meniscal scaffold for the treatment of medial meniscus deficiency," Knee Surgery, Sports Traumatology, Arthroscopy, 2014. 
[61] C. Baynat, C. Andro, J. P. Vincent et al., "Actifit synthetic meniscal substitute: experience with 18 patients in Brest, France," Orthopaedics \& Traumatology: Surgery \& Research, vol. 100, no. 8, supplement, pp. S385-S389, 2014.

[62] U. Koller, S. Nehrer, P. Vavken, B. Kapeller, R. Windhager, and C. Chiari, "Polyethylene terephthalate (PET) enhances chondrogenic differentiation of ovine meniscocytes in a hyaluronic acid/polycaprolactone scaffold in vitro," International Orthopaedics, vol. 36, no. 9, pp. 1953-1960, 2012.

[63] B. M. Baker and R. L. Mauck, "The effect of nanofiber alignment on the maturation of engineered meniscus constructs," Biomaterials, vol. 28, no. 11, pp. 1967-1977, 2007.

[64] M. B. Fisher, E. A. Henning, N. Söegaard, J. L. Esterhai, and R. L. Mauck, "Organized nanofibrous scaffolds that mimic the macroscopic and microscopic architecture of the knee meniscus," Acta Biomaterialia, vol. 9, no. 1, pp. 4496-4504, 2013.

[65] C. Chiari, U. Koller, R. Dorotka et al., "A tissue engineering approach to meniscus regeneration in a sheep model," Osteoarthritis and Cartilage, vol. 14, no. 10, pp. 1056-1065, 2006.

[66] K. R. Myers, N. A. Sgaglione, and A. D. Goodwillie, "Meniscal scaffolds," The Journal of Knee Surgery, vol. 27, no. 6, pp. 435442, 2014.

[67] R. Verdonk, P. Verdonk, W. Huysse, R. Forsyth, and E.-L. Heinrichs, "Tissue ingrowth after implantation of a novel, biodegradable polyurethane scaffold for treatment of partial meniscal lesions," American Journal of Sports Medicine, vol. 39, no. 4, pp. 774-782, 2011.

[68] H. E. Gruber, D. Mauerhan, Y. Chow et al., "Three-dimensional culture of human meniscal cells: extracellular matrix and proteoglycan production," BMC Biotechnology, vol. 8, article 54, 2008.

[69] J. M. Zaleskas, B. Kinner, T. M. Freyman, I. V. Yannas, L. J. Gibson, and M. Spector, "Growth factor regulation of smooth muscle actin expression and contraction of human articular chondrocytes and meniscal cells in a collagen-GAG matrix," Experimental Cell Research, vol. 270, no. 1, pp. 21-31, 2001.

[70] A. Marsano, D. Wendt, R. Raiteri et al., "Use of hydrodynamic forces to engineer cartilaginous tissues resembling the nonuniform structure and function of meniscus," Biomaterials, vol. 27, no. 35, pp. 5927-5934, 2006.

[71] C. Chiari, U. Koller, B. Kapeller, R. Dorotka, U. Bindreiter, and S. Nehrer, "Different behavior of meniscal cells in collagen II/I,III and Hyaff-11 scaffolds in vitro," Tissue Engineering — Part A, vol. 14, no. 8, pp. 1295-1304, 2008.

[72] G.-K. Tan, D. L. M. Dinnes, P. T. Myers, and J. J. CooperWhite, "Effects of biomimetic surfaces and oxygen tension on redifferentiation of passaged human fibrochondrocytes in $2 \mathrm{D}$ and 3D cultures," Biomaterials, vol. 32, no. 24, pp. 5600-5614, 2011.

[73] M. Petri, K. Ufer, I. Toma et al., "Effects of perfusion and cyclic compression on in vitro tissue engineered meniscus implants," Knee Surgery, Sports Traumatology, Arthroscopy, vol. 20, no. 2, pp. 223-231, 2012.

[74] J. C. Monllau, P. E. Gelber, F. Abat et al., "Outcome after partial medial meniscus substitution with the collagen meniscal implant at a minimum of 10 years' follow-up," ArthroscopyJournal of Arthroscopic and Related Surgery, vol. 27, no. 7, pp. 933-943, 2011.

[75] S. Zaffagnini, G. M. Marcheggiani Muccioli, N. Lopomo et al., "Prospective long-term outcomes of the medial collagen meniscus implant versus partial medial meniscectomy: a minimum 10-year follow-up study," The American Journal of Sports Medicine, vol. 39, no. 5, pp. 977-985, 2011.

[76] B. B. Mandal, S.-H. Park, E. S. Gil, and D. L. Kaplan, "Multilayered silk scaffolds for meniscus tissue engineering," Biomaterials, vol. 32, no. 2, pp. 639-651, 2011.

[77] B. B. Mandal, S.-H. Park, E. S. Gil, and D. L. Kaplan, "Stem cellbased meniscus tissue engineering," Tissue Engineering, Part A, vol. 17, no. 21-22, pp. 2749-2761, 2011.

[78] H. Martínez, C. Brackmann, A. Enejder, and P. Gatenholm, "Mechanical stimulation of fibroblasts in micro-channeled bacterial cellulose scaffolds enhances production of oriented collagen fibers," Journal of Biomedical Materials Research Part A, vol. 100, no. 4, pp. 948-957, 2012.

[79] K. R. Stone, W. G. Rodkey, R. Webber, L. McKinney, and J. R. Steadman, "Meniscal regeneration with copolymeric collagen scaffolds. In vitro and in vivo studies evaluated clinically, histologically, and biochemically," The American Journal of Sports Medicine, vol. 20, no. 2, pp. 104-111, 1992.

[80] W. G. Rodkey, K. E. DeHaven, W. H. Montgomery III et al., "Comparison of the collagen meniscus implant with partial meniscectomy. A prospective randomized trial," The Journal of Bone and Joint Surgery-American Volume, vol. 90, no. 7, pp. 1413-1426, 2008.

[81] G.-K. Tan, D. L. M. Dinnes, L. N. Butler, and J. J. Cooper-White, "Interactions between meniscal cells and a self assembled biomimetic surface composed of hyaluronic acid, chitosan and meniscal extracellular matrix molecules," Biomaterials, vol. 31, no. 23, pp. 6104-6118, 2010.

[82] R. Valluzzi, S. Winkler, D. Wilson, and D. L. Kaplan, "Silk: molecular organization and control of assembly," Philosophical Transactions of the Royal Society B: Biological Sciences, vol. 357, no. 1418, pp. 165-167, 2002.

[83] J. J. Rongen, T. G. van Tienen, B. van Bochove, D. W. Grijpma, and P. Buma, "Biomaterials in search of a meniscus substitute," Biomaterials, vol. 35, no. 11, pp. 3527-3540, 2014.

[84] H. Bäckdahl, G. Helenius, A. Bodin et al., "Mechanical properties of bacterial cellulose and interactions with smooth muscle cells," Biomaterials, vol. 27, no. 9, pp. 2141-2149, 2006.

[85] A. Bodin, S. Concaro, M. Brittberg, and P. Gatenholm, "Bacterial cellulose as a potential meniscus implant," Journal of Tissue Engineering and Regenerative Medicine, vol. 1, no. 6, pp. 406408, 2007.

[86] K. S. Soppimath, T. M. Aminabhavi, A. M. Dave, S. G. Kumbar, and W. E. Rudzinski, "Stimulus-responsive 'smart' hydrogels as novel drug delivery systems," Drug Development and Industrial Pharmacy, vol. 28, no. 8, pp. 957-974, 2002.

[87] M. Kobayashi, J. Toguchida, and M. Oka, "Development of an artificial meniscus using polyvinyl alcohol-hydrogel for early return to, and continuance of, athletic life in sportspersons with severe meniscus injury. I: mechanical evaluation," The Knee, vol. 10, no. 1, pp. 47-51, 2003.

[88] M. Kobayashi, J. Toguchida, and M. Oka, "Development of an artificial meniscus using polyvinyl alcohol-hydrogel for early return to, and continuance of, athletic life in sportspersons with severe meniscus injury. II: animal experiments," The Knee, vol. 10, no. 1, article 53, 2003.

[89] M. Kobayashi, "A study of polyvinyl alcohol-hydrogel (PVA$\mathrm{H})$ artificial meniscus in vivo," Bio-Medical Materials and Engineering, vol. 14, no. 4, pp. 505-515, 2004. 
[90] M. Kobayashi, Y.-S. Chang, and M. Oka, "A two year in vivo study of polyvinyl alcohol-hydrogel (PVA-H) artificial meniscus," Biomaterials, vol. 26, no. 16, pp. 3243-3248, 2005.

[91] S. P. Grogan, P. H. Chung, P. Soman et al., "Digital micromirror device projection printing system for meniscus tissue engineering," Acta Biomaterialia, vol. 9, no. 7, pp. 7218-7226, 2013.

[92] M. Sarem, F. Moztarzadeh, and M. Mozafari, "How can genipin assist gelatin/carbohydrate chitosan scaffolds to act as replacements of load-bearing soft tissues?" Carbohydrate Polymers, vol. 93, no. 2, pp. 635-643, 2013.

[93] W. W. Thein-Han, J. Saikhun, C. Pholpramoo, R. D. K. Misra, and Y. Kitiyanant, "Chitosan-gelatin scaffolds for tissue engineering: physico-chemical properties and biological response of buffalo embryonic stem cells and transfectant of GFP-buffalo embryonic stem cells," Acta Biomaterialia, vol. 5, no. 9, pp. 34533466, 2009.

[94] M. Sarem, F. Moztarzadeh, M. Mozafari, and V. P. Shastri, "Optimization strategies on the structural modeling of gelatin/chitosan scaffolds to mimic human meniscus tissue," Materials Science \& Engineering C: Materials for Biological Applications, vol. 33, no. 8, pp. 4777-4785, 2013.

[95] K. Ishida, R. Kuroda, M. Miwa et al., "The regenerative effects of platelet-rich plasma on meniscal cells in vitro and its in vivo application with biodegradable gelatin hydrogel," Tissue Engineering, vol. 13, no. 5, pp. 1103-1112, 2007.

[96] Y. Zhu, M. Yuan, H. Y. Meng et al., "Basic science and clinical application of platelet-rich plasma forcartilage defects and osteoarthritis: a review," Osteoarthritis and Cartilage, vol. 21, no. 11, pp. 1627-1637, 2013.

[97] J. A. Simson, I. A. Strehin, B. W. Allen, and J. H. Elisseeff, "Bonding and fusion of meniscus fibrocartilage using a novel chondroitin sulfate bone marrow tissue adhesive," Tissue Engineering, Part A, vol. 19, no. 15-16, pp. 1843-1851, 2013.

[98] J. J. Ballyns, T. M. Wright, and L. J. Bonassar, "Effect of media mixing on ECM assembly and mechanical properties of anatomically-shaped tissue engineered meniscus," Biomaterials, vol. 31, no. 26, pp. 6756-6763, 2010.

[99] H. Minehara, K. Urabe, K. Naruse et al., "A new technique for seeding chondrocytes onto solvent-preserved human meniscus using the chemokinetic effect of recombinant human bone morphogenetic protein-2," Cell and Tissue Banking, vol. 12, no. 3, pp. 199-207, 2011.

[100] G. H. Sandmann, S. Eichhorn, S. Vogt et al., "Generation and characterization of a human acellular meniscus scaffold for tissue engineering," Journal of Biomedical Materials ResearchPart A, vol. 91, no. 2, pp. 567-574, 2009.

[101] T. W. Stapleton, J. Ingram, J. Katta et al., "Development and characterization of an acellular porcine medial meniscus for use in tissue engineering," Tissue Engineering: Part A, vol. 14, no. 4, pp. 505-518, 2008.

[102] D. Maier, K. Braeun, E. Steinhauser et al., "In vitro analysis of an allogenic scaffold for tissue-engineered meniscus replacement," Journal of Orthopaedic Research, vol. 25, no. 12, pp. 1598-1608, 2007.

[103] K. J. Stabile, D. Odom, T. L. Smith et al., "An acellular, allograftderived meniscus scaffold in an ovine model," Arthroscopy, vol. 26, no. 7, pp. 936-948, 2010.

[104] A. Azhim, T. Ono, Y. Fukui, Y. Morimoto, K. Furukawa, and T. Ushida, "Preparation of decellularized meniscal scaffolds using sonication treatment for tissue engineering," in Proceedings of the 35th Annual International Conference of the IEEE Engineering in Medicine and Biology Society (EMBC '13), pp. 6953-6956, IEEE, Osaka, Japan, July 2013.

[105] C. H. Lee, S. A. Rodeo, L. A. Fortier, C. Lu, C. Erisken, and J. J. Mao, "Protein-releasing polymeric scaffolds induce fibrochondrocytic differentiation of endogenous cells for knee meniscus regeneration in sheep," Science Translational Medicine, vol. 6, no. 266, Article ID 266ra171, 2014.

[106] J. J. Ballyns, J. P. Gleghorn, V. Niebrzydowski et al., "Imageguided tissue engineering of anatomically shaped implants via MRI and micro-CT using injection molding," Tissue Engineering-Part A, vol. 14, no. 7, pp. 1195-1202, 2008.

[107] U. G. Longo, G. Rizzello, A. Berton et al., "A review of preclinical and clinical studies using synthetic materials for meniscus replacement," Current Stem Cell Research \& Therapy, vol. 8, no. 6, pp. 438-443, 2013. 

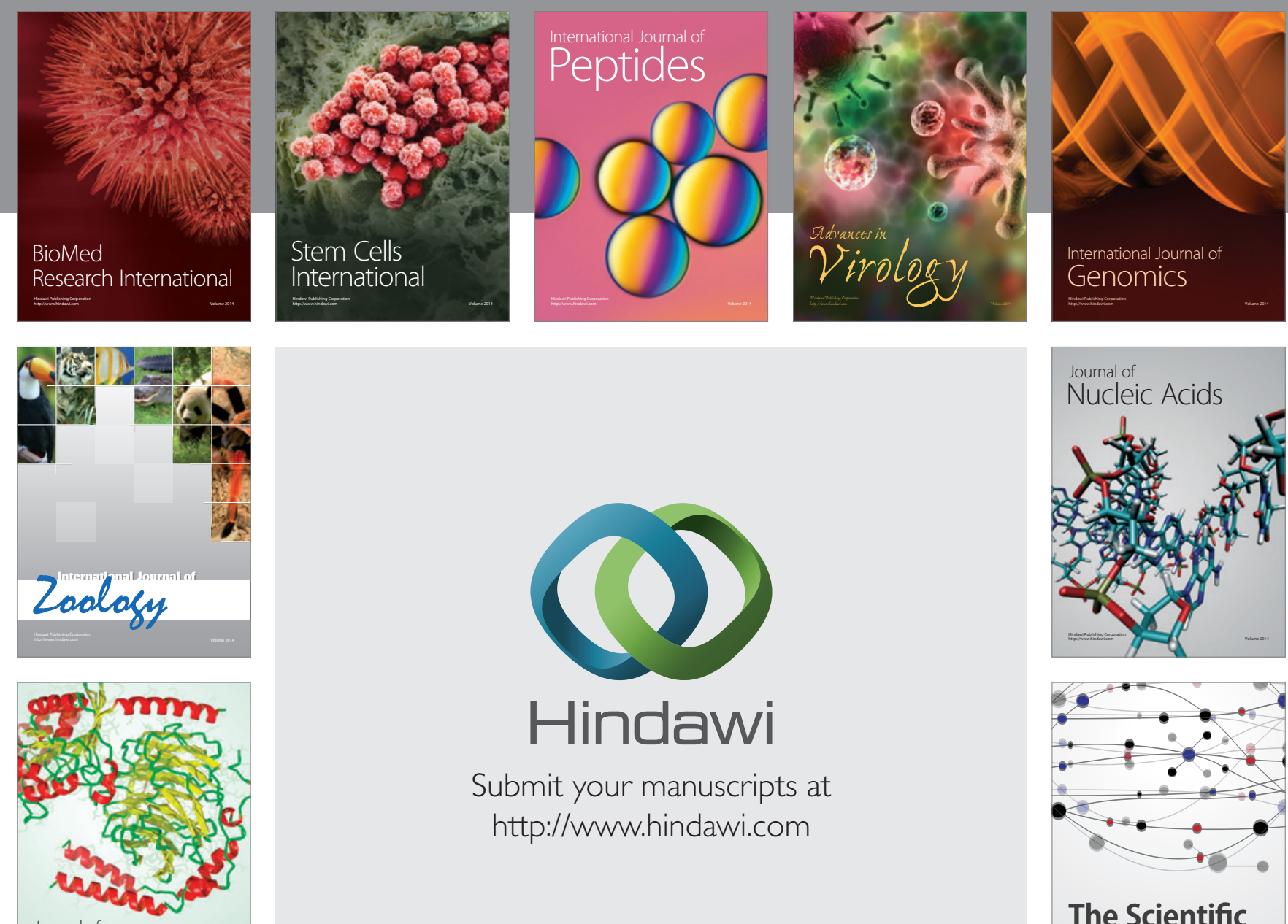

Submit your manuscripts at

http://www.hindawi.com

Journal of
Signal Transduction
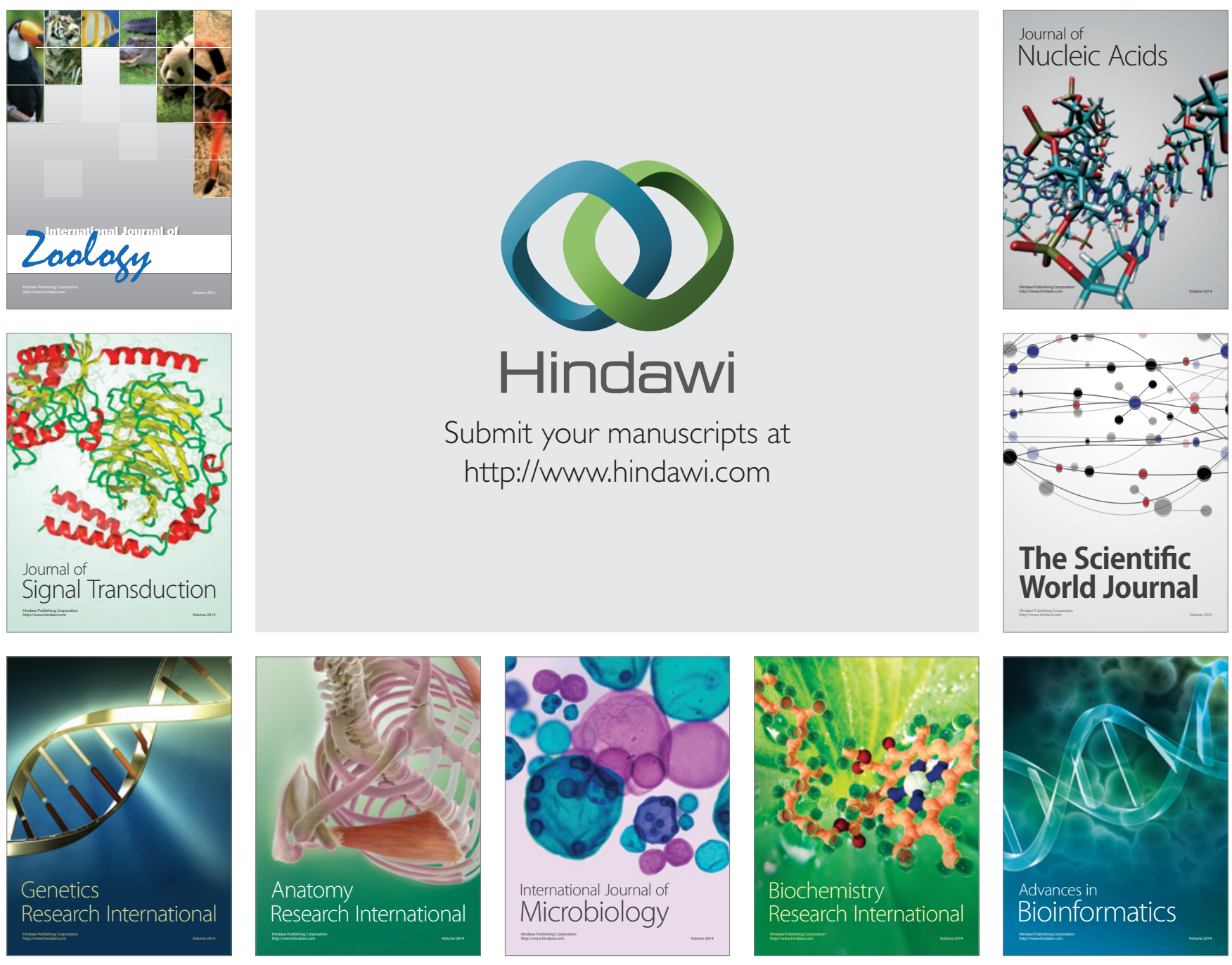

The Scientific World Journal
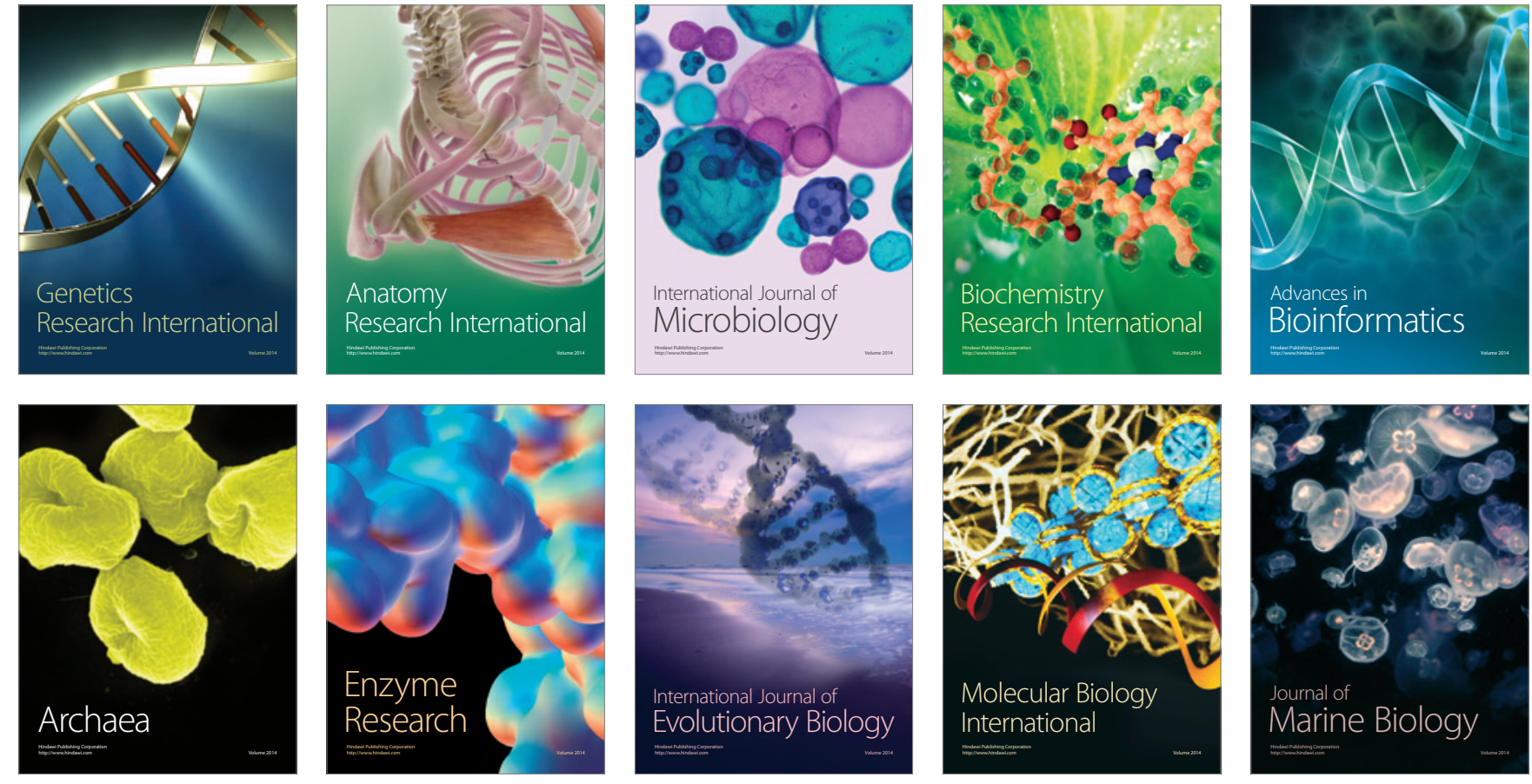